\title{
Pollination by nitidulid beetles in the hemi-epiphytic aroid Monstera lentii (Araceae: Monsteroideae)
}

\author{
Danyi Prieto ${ }^{\mathrm{a}}$, Alfredo Cascante-Marín ${ }^{\mathrm{b}, *}$ \\ a Escuela de Ciencias Biológicas, Universidad Nacional de Costa Rica, Heredia, Costa Rica \\ bscuela de Biología, Universidad de Costa Rica, 11501-2060 San Pedro de Montes de Oca, San José, Costa Rica
}

\section{A R T I C L E I N F O}

\section{Article history:}

Received 7 November 2016

Received in revised form 19 April 2017

Accepted 19 April 2017

Edited by Stefan Dötterl

Available online 24 April 2017

\section{Keywords:}

Cantharophily

Drosophilid flies

Floral chamber

Beetle pollination

Stingless bees

Thermogenesis

\begin{abstract}
A B S T R A C T
Among aroids (Araceae family) with bisexual flowers, the reproductive biology of the neotropical genus Monstera (Subfamily Monsteroideae) is misunderstood. Nothing is known about the reproductive phenology and the sparse evidence on its pollination system is equivocal, suggesting both bees and beetles as pollinators. In order to elucidate the pollination system and reproductive behavior of Monstera, we documented the floral cycle, spathe movement, floral visitors, and heat production of the inflorescence, and the flowering and fruiting phenology of $M$. lentii in a montane forest in Costa Rica. We found that $M$. lentii was mainly visited and likely pollinated by nitidulid beetles (Cychrocephalus corvinus, Nitidulidae) from the Mystropini tribe, which were mainly known as palm pollinators so far. In this mutualism, the beetles use the floral chamber as shelter, mating place, and probably as brood site. Drosophilid flies also visited the inflorescences and might participate in a mixed-pollination system, while stingless bees are considered as pollen robbers. Flowering and fruiting peaks occurred during the rainy season. Floral development was protogynous, a mechanism likely to prevent self-pollination. We concluded that pollination in M. lentii represents a highly dependent system on biotic pollinators for successful fruit set which likely contributes to an out-crossed mating system. Our findings indicate that pollination systems of bisexual aroids are more diverse than previously suggested.
\end{abstract}

C 2017 Elsevier GmbH. All rights reserved.

\section{Introduction}

The Araceae family (aroids) is among the most diverse flowering plants in tropical and subtropical regions, with ca. 3750 species distributed among 125 genera worldwide (Boyce and Croat, 2016). Aroids are herbaceous monocotyledons characterized by displaying diverse growth habits; from mostly terrestrial to epiphytic and hemi-epiphytic (Bown, 2000). The characteristic reproductive structures of aroids have a common design composed of a leaflike bract (spathe) that subtends and sometimes encloses the spike (spadix); a terminal fleshy axis that bears the small and highly modified flowers (Grayum, 1990). Two groups within Araceae are distinguished according to their sexual expression, one of them consists of bisexual basal groups (bearing hermaphroditic flowers) from the Pothoideae and Monsteroideae subfamilies; and the other comprises monoecious species (bearing staminate and pistillate flowers arranged in separated sections of the spadix) mainly from the Aroideae subfamily (Cusimano et al., 2011; Grayum, 1990).

\footnotetext{
* Corresponding author.

E-mail address: alfredo.cascante@ucr.ac.cr (A. Cascante-Marín).
}

Pollination mechanisms of aroids have been mostly documented in monoecious genera of the subfamily Aroideae from the neotropics (Dieffenbachia, Philodendron, and Xanthosoma) and paleotropics (Amorphophallus, Arisaema, and Arum) (reviewed in Gibernau, 2003, 2011). Pollination of aroids involves insects (mainly beetles, flies, and bees), dichogamous (protogyny) floral development, and short anthesis periods (1-2 d) in monoecious species versus longer periods in bisexual species. Among monoecious groups, the spathe frequently encloses the spadix, a floral chamber develops and heat is produced by the spadix (Gibernau and Barabé, 2000, 2002; Gibernau et al., 1999; Maia et al., 2010). Heat production or thermogenesis has been associated to the emission of volatiles to attract pollinators (mainly beetles and flies) during floral anthesis (Gibernau and Barabé, 2002; Gottsberger and Amaral, 1984; Gottsberger et al., 2013; Seymour, 1999) and insect thermic reward (Seymour et al., 2003). In some cases, insects are attracted to the floral chamber by deceptive means, imprisoned and later released through movement of the spathe in a mechanism known as "trap-pollination" (Dafni, 1984). Pollination by trap mechanisms have appeared at least ten times in the aroid family and is present in 27 genera (Bröderbauer et al., 2012). 
The few pollination studies of bisexual aroids include species from the subfamilies Pothoideae (Anthurium) and Monsteroideae (Monstera and Spathiphyllum) (Etl et al., 2017; reviewed in Gibernau, 2003, 2011, 2016). These groups apparently do not develop a floral chamber nor trap-pollination mechanisms (Bröderbauer et al., 2012). The pollination ecology of Monstera (60 spp.) has received little attention and the scanty evidence is contradictory (Gibernau et al., 2010). Monstera is exclusive to Tropical America and one major center of diversity locates in southern Mesoamerica between Costa Rica and Panama (Grayum, 2003). Stingless bees have been reported as visitors to inflorescences when the spathe is fully opened (Madison, 1977; Ramírez and Gómez, 1978); while beetle pollination was suggested by Chouteau et al. (2007). Thus far, the latter work is the only detailed pollination study available from a Monstera species. Chouteau et al. (2007) described a pattern of spathe unfurling, formation of a floral chamber and heat production in M. obliqua in French Guiana. Additional cases of thermogenesis in the genus have been reported for $M$. adansonii and $M$. deliciosa from cultivated plants ex-situ (Chouteau et al., 2009). At present, however, it is unclear the potential role of the floral chamber and thermogenesis in the pollination system of Monstera.

Knowledge on pollination systems of bisexual aroids is necessary to understand the evolution of pollination mechanisms in this diverse plant family (see Bröderbauer et al., 2012; Chartier et al., 2014; Gibernau et al., 2010). Documenting the reproductive biology, phenology and pollinators of rare and geographically restricted plant species provides key information for their conservation. The aim of this study is to increase the knowledge on the pollination systems of bisexual aroids by studying the pollination ecology and reproductive phenology of a Monstera species endemic to humid and cloud montane forests from southern Mesoamerica. We tested for cantharophily in Monstera lentii as previously documented for M. obliqua (Chouteau et al., 2007). We specifically aimed at describing (i) the floral cycle in relation to spathe movement and floral visitors/pollinators, (ii) the pattern of thermogenesis, (iii) the population flowering and fruiting phenology, and (iv) the female reproductive success and spontaneous self-pollination.

\section{Materials and methods}

\subsection{Study site and species}

Field work was conducted in a montane cloud forest fragment in the vicinity of the Central Valley of Costa Rica, Cartago province $\left(9^{\circ} 52^{\prime}-9^{\circ} 54 \mathrm{~N}, 83^{\circ} 57^{\prime}-84^{\circ} 00^{\prime} \mathrm{W}\right)$, known as Cerros La Carpintera, which is on the northern limit of the Talamanca Mountain Range. The mountainous terrain rises from 1500 to $1850 \mathrm{~m}$ asl, and the forested area (ca. $840 \mathrm{ha}$ ) is a mixture of irregular primary forest remnants intermixed with old growth secondary forest ( $+75 \mathrm{y}$ old) covering the ridge and upper slopes and surrounded by open pastures and tree pastures. Oaks (Quercus spp.), fig-trees (Ficus spp.), and members of the avocado family (Lauraceae) are representative forest canopy trees (Sánchez et al., 2008).

Climate is seasonal with a dry season $(<100 \mathrm{~mm}$ per month) from December to April and the wettest period from October to November. Mean annual precipitation is $1839 \mathrm{~mm}$ and mean annual temperature $16^{\circ} \mathrm{C}$. The forested area near the mountain ridge (above $1700 \mathrm{~m}$ ) is characterized by frequent cloudiness and foggy conditions during the early morning. The site represents a Premontane Wet Forest with a transition to Lower Montane Wet Forest on the upper sites according to the Holdridge's Life Zones System (Bolaños and Watson, 1993).

Monstera lentii Croat \& Grayum is a geographically restricted species from montane wet and cloud forests of the Talamanca

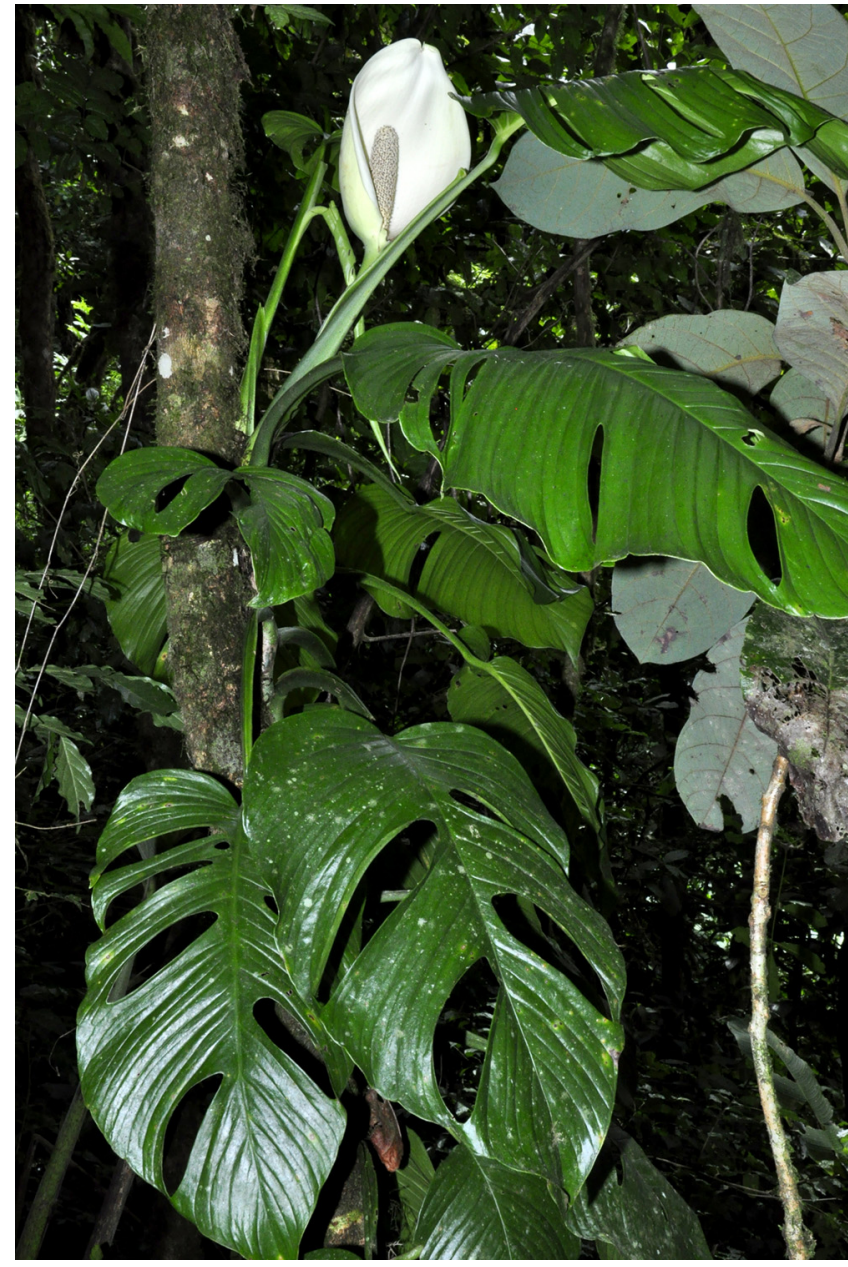

Fig 1. Plant habit of the hemi-epiphyte Monstera lentii (Araceae) in the understory of a montane forest, Costa Rica. Reproductive individual displaying an inflorescence in male phase; note the white spathe fully opened and exposing the spadix.

Mountain Range in Costa Rica and Western Panama, from 1300 to $1700 \mathrm{~m}$ asl (Grayum, 2003). At the study site, M. lentii grows sympatrically with the less abundant $M$. adansonii Schott, $M$. oreophila Madison, and M. punctulata (Schott) Schott ex Engl. (Sánchez et al., 2008). M. lentii inhabits the forest understory as a secondary hemi-epiphyte. After germinating in the ground the stems grow horizontally until they reach a host-tree to climb by means of adventitious roots up to a height of 3-5 $\mathrm{m}$ above the ground. Leaf blades of $M$. lentii adults are often fenestrated, $28-60 \times 18-41 \mathrm{~cm}$ in size (Grayum 2003; Fig. 1). The small flowers lack a perianth and are borne on a spadix $5-16 \mathrm{~cm}$ long, covered by a green spathe; the protuberant conical or cylindrical style with a capitate stigma distinguishes M. lentii from related species (Grayum 2003). The ovary is protected by a thick tissue formed by the stylar portion of the pistil (Madison, 1977); sterile flowers (mean $=66 \pm 20$ S.D., $N=18$ ) are borne at the spadix base in the studied species, which represents in average $12 \%$ of all the flowers from an inflorescence. Voucher specimens are deposited in the Herbarium USJ of the University of Costa Rica.

\subsection{Inflorescence development, anthesis, and floral visitors}

In order to describe the floral cycle in relation to the spathe movement and floral visitors, we followed the development of 12 inflorescences from 10 plants in field conditions. We carried out direct observations at 3-h intervals in September 2009 and July 


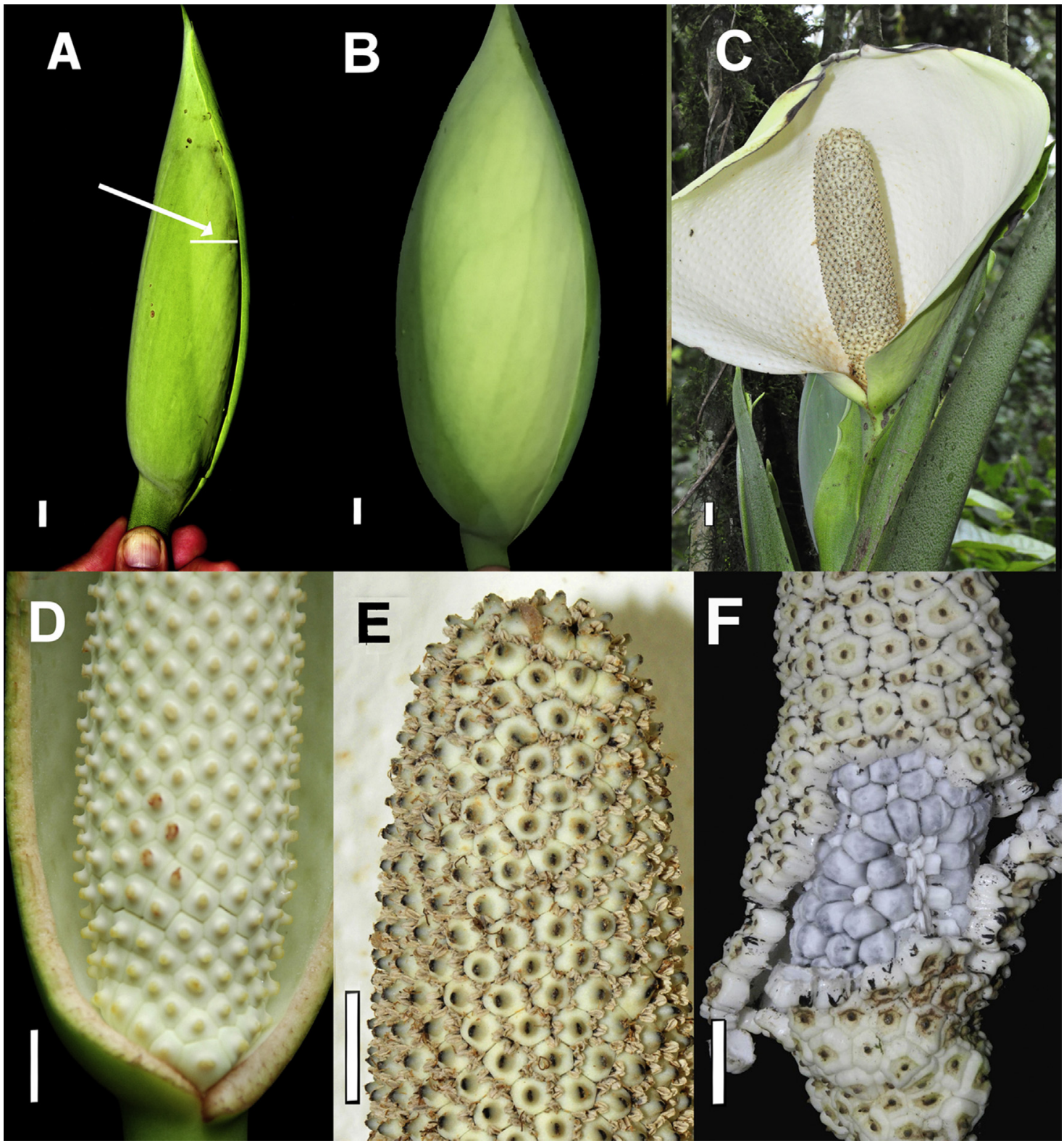

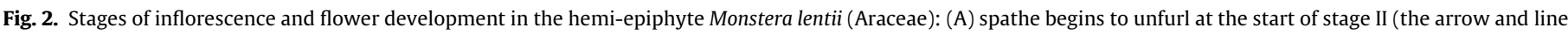

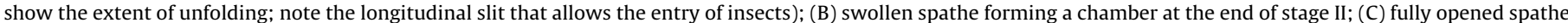

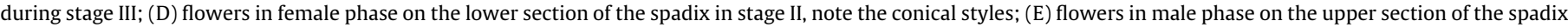

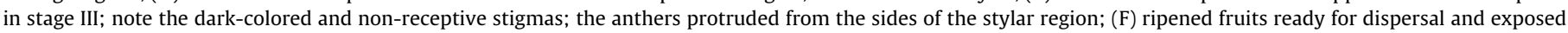
after the protective stylar region sets apart. Scale bars $=10 \mathrm{~mm}$. Refer to Table 1 for stage descriptions.

2010 and recorded: i) spathe behavior (closed, unfurling and fully open; Fig. 2A-C), ii) female anthesis by visual inspection of the stigma's appearance (receptive if light colored and with a transparent secretion or senescent if dry and dark-brown in color, indicating the end of the receptive condition; Fig. 2D-E), iv) male anthesis when pollen was presented (anthers visible and exposing the pollen grains; Fig. 2E), and v) scent emission by smelling the inflorescence.

Preliminary observations revealed that during the female phase the spathe remained closed (i.e., enclosing the spadix), thus it was necessary to make a window in the spathe by cutting a $2 \mathrm{~cm}^{2}$ section to facilitate visual inspection. This manipulation had no apparent effect in the inflorescence development. In the same inflorescences used to describe the flowering cycle, we also recorded the presence, behavior and relative abundance (visually estimated) of floral visitors. Six additional inflorescences in female phase and prior to spathe full opening were collected during the population flower- ing peak to determine the absolute abundance and identity of floral visitors in the floral chamber.

\subsection{Heat production in the inflorescence}

We measured in-situ thermogenesis in four inflorescences from different plants in August 2015. We used an Amprobe TMD-56 multilogging digital thermocouple thermometer (Amprobe Test Tools Inc., WA, USA) to automatically record the ambient temperature and the temperature inside the floral chamber at 1 -min reading intervals during the female and male floral phase $(4 \mathrm{~d})$, which spanned the period of spathe unfolding. One probe was inserted in the floral chamber through a small hole in the spathe and positioned in the space between the spathe and the spadix; the additional probe recorded air temperature $20-30 \mathrm{~cm}$ away from the inflorescence and protected from direct rainfall and sunlight. 


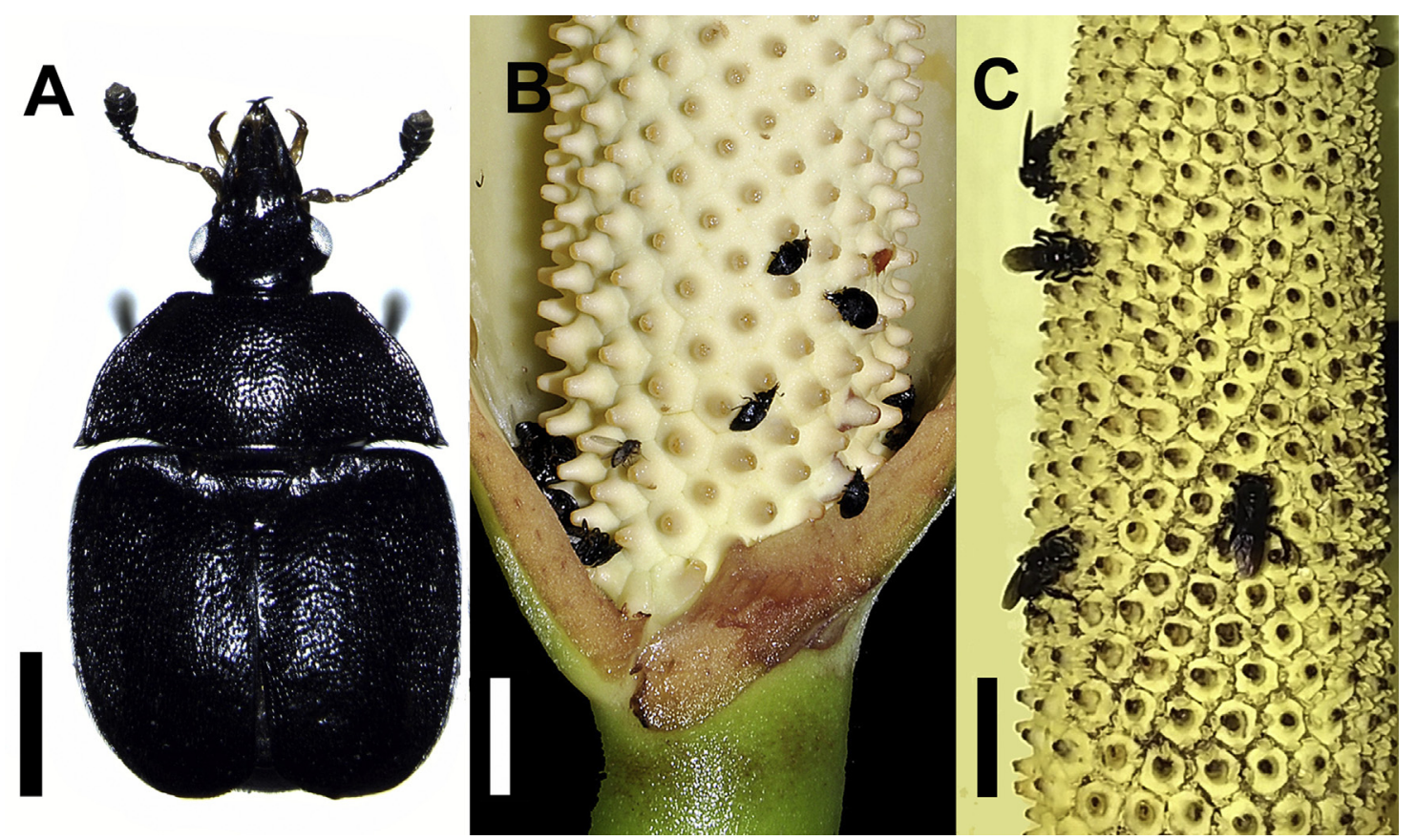

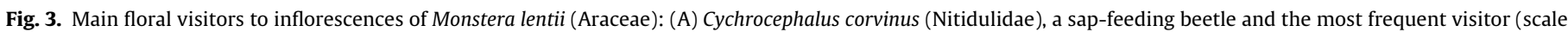

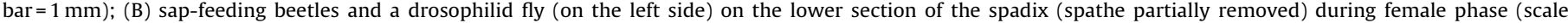
bar $=10 \mathrm{~mm}$ ); (C) stingless bees collecting pollen during male phase when the spathe has fully opened (scale bar $=10 \mathrm{~mm})$.

Table 1

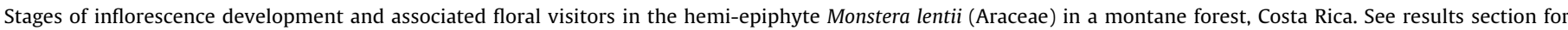
complete descriptions.

\begin{tabular}{|c|c|c|c|}
\hline \multirow[b]{2}{*}{ Characteristics } & \multicolumn{3}{|l|}{ Inflorescence stage } \\
\hline & Stage I & Stage II & Stage III \\
\hline Sexual phase & . & female & male \\
\hline Spathe behavior & unfurling/swells & slit opening/closing & fully opening \\
\hline Duration (days) & $3-4$ & 3 & 2 \\
\hline \multicolumn{4}{|l|}{ Insect visitors: } \\
\hline Sap-feeding beetles & - & ++ & ++ \\
\hline Flies & + & ++ & ++ \\
\hline Stingless bees & - & - & ++ \\
\hline
\end{tabular}

Relative abundance: (-)absent, (+) frequent, (++) abundant.

\subsection{Reproductive success and spontaneous self-pollination}

Female reproductive success under natural pollination conditions was determined in a sample of 18 infructescenses from different plants collected 24-34 weeks after anthesis when fruits have ripened. Fruits were assigned to one of the following categories: i) developed (with seeds) and ii) aborted (seed stunted). Reproductive success was defined as the percentage of developed fruits relative to the number of flowers per inflorescences (excluding the basal sterile flowers). The number of seeds on developed fruits was also recorded. The capacity for spontaneous self-pollination was evaluated by bagging 11 inflorescences with fine mesh fabric bags (pore size $<0.5 \mathrm{~mm}$ ) before spathe unfurling to exclude floral visitors.

\subsection{Population reproductive phenology}

We monitored 70 adult plants of $M$. lentii distributed over four sites separated from 100 to $700 \mathrm{~m}$ apart. Plants per site varied from 13 to 23 and were identified with a numbered aluminum plate. To determine the flowering and fruiting phenology, we conducted weekly observations of the reproductive status of each plant from April 2009 to March 2010. At each census, we recorded each plant as: i) developing inflorescences (spathe closed), ii) flowering (spathe unfurling or recently open), iii) fruit maturation (spathe shriveling up or fallen and fruits swelling) and, iv) fruit dispersal (stylar portion of the pistil detaching and exposing the fruits; Fig. 2F).

\section{Results}

\subsection{Inflorescence development, anthesis, and floral visitors}

Inflorescences emerged from the upper leaf axils and each plant produced an average of 4.8 ( \pm 2.9 S.D.) inflorescences during the study year. The spathe enclosing the spadix was in vertical position while the peduncle remained covered by the petiole sheath. The floral cycle at the inflorescence level initiated when the spathe started to unfurl and terminated when it was fully opened, after 8-9 days. During that period, we identified three stages associated to changes in spathe behavior, sexual expression, and floral visitors (Table 1). Stage I began when the greenish spathe started to slowly unfurl for 3-4 days. The spathe's outer margin left a lighter green area on the inner fold that allowed recognition of this phase (Fig. 2A). By the end of this stage, the inflorescence had swollen forming a floral chamber between the spathe and the spadix (Fig. 2B). A slit (Fig. 2A) formed 

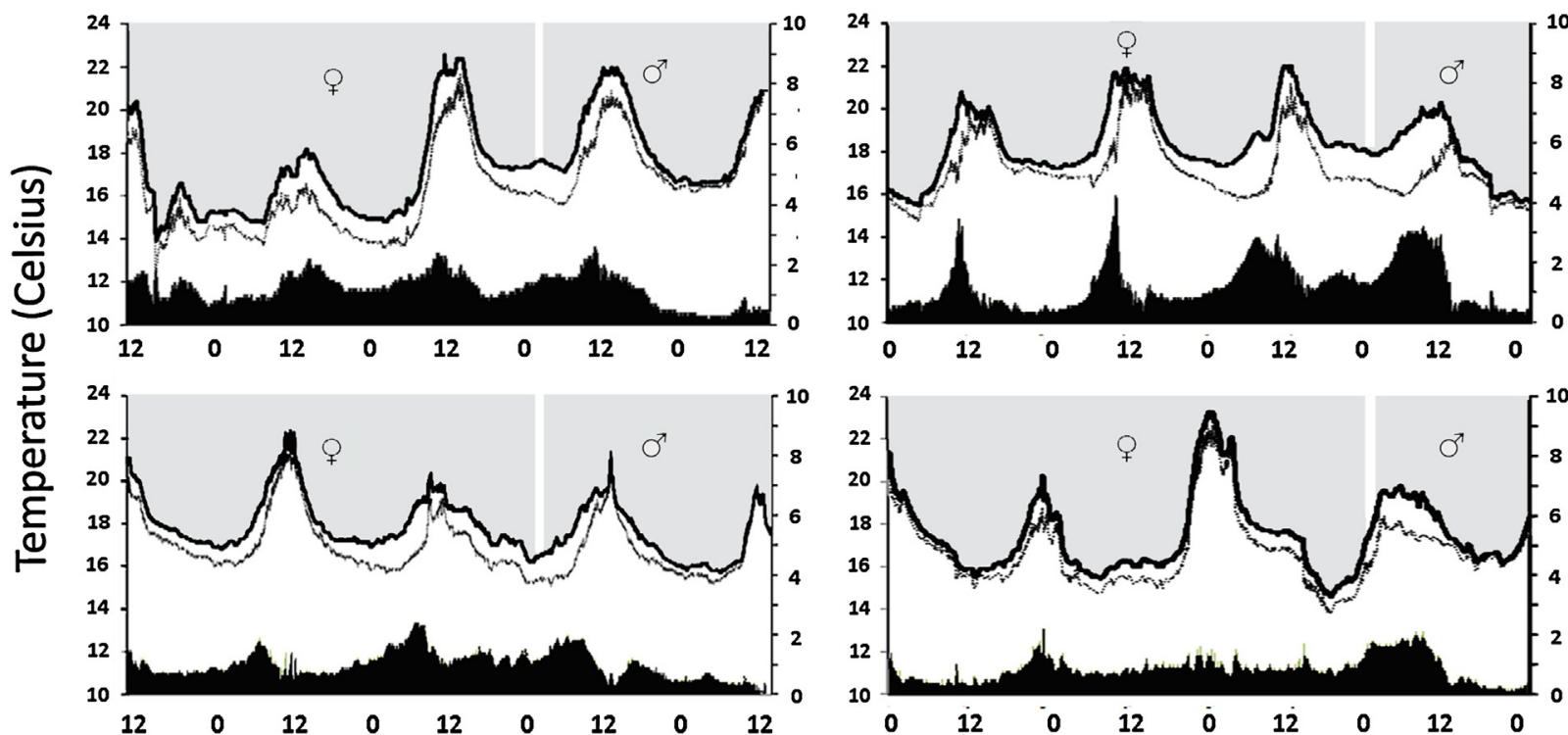

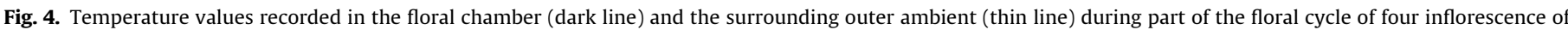

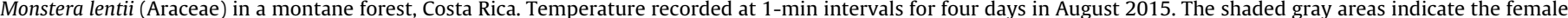
(stage II) and male (stage III) phase. The dark area represents the temperature difference between records from the floral chamber and the outer ambient.

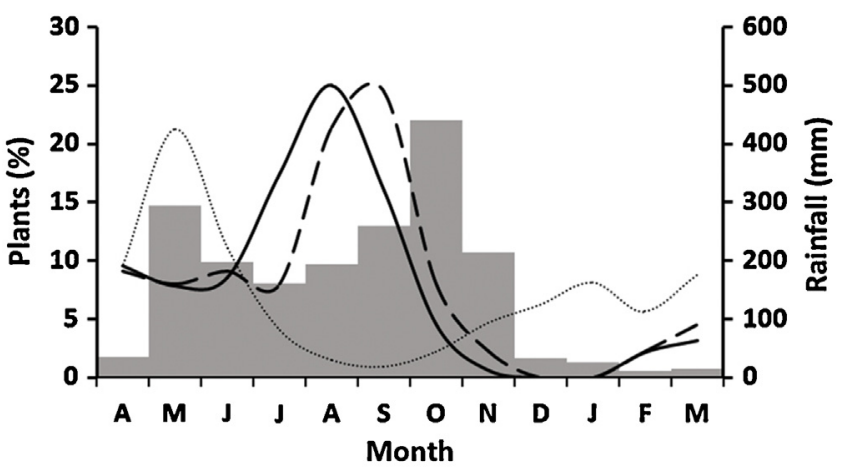

Fig. 5. Reproductive phenology of the hemi-epiphyte Monstera lentii (Araceae) in a montane forest, Costa Rica. Data from April 2009 to March 2010 ( $\mathrm{N}=70$ plants): inflorescence development (continuous line), flowering (dashed line), and seed dispersal (dotted line). Average monthly values of precipitation are also indicated (gray bars). Precipitation data from 2008 to 2010 recorded at the Iztarú Weather Station (No. 84181 ) located at the study site (Instituto Meteorológico Nacional, unpubl. data).

by the unfurling spathe was visible on the upper section of the inflorescence. We observed drosophilid flies (Drosophilidae: Drosophila, subgenus Phloridosa) entering the floral chamber through the slit at the end of this stage. A slight bittersweet fragrance was perceptible.

Stage II lasted three days and encompassed the female phase. The spathe continued unfurling but was still enclosing the spadix (Fig. 2B). We observed small (ca. $5 \mathrm{~mm}$ ) nitidulid beetles (Cychrocephalus corvinus Reitter 1873, Nitidulidae; Fig. 3A) mainly arriving the morning hours and entering the floral chamber through the slit on the spathe. Each day during this stage, an increase in scent was perceptible around noon (10:00-12:00 h) and has faded around dusk $(18: 00 \mathrm{~h})$. The slit on the spathe closed during the second day of this stage and prevented the insects from leaving the floral chamber; however, sometimes an opening remained near the spathe tip. The beetles and flies were active at night and daytime, wandering on the spadix and copulating (Fig. 3B). We recorded an average of 97 ( \pm 42 S.D.) beetles and 28 ( \pm 24 S.D.) flies per inflorescence at this stage. By the third day of the beetles' arrival, the stigmas had turned dark brown and appeared dry, indicating the end of the female phase. There was not apparent overlap between the female and male anthesis.

On the first day of stage III, we observed the anthers protruding from between the tightly arranged flowers in the early morning. Pollen presentation started when the spadix was still enclosed by the spathe. Later that day at around 20:00 h, the spadix was covered with sweet-smelling pollen. In the morning hours of the second day of this stage, the spathe fully opened and exposed the spadix (Fig. 2C). At that moment, the spathe turned whitish green outside and white in the inside. During the second day of stage III, we observed that beetles and flies stayed at the spadix base where fallen pollen grains accumulated and later departed with pollen on their bodies. We also observed some beetle larvae at the base of the spadix. Sometime later, stingless bees (Partamona orizabaensis (Strand 1919), Meliponini) arrived to actively collect pollen grains (Fig. 3C). Following the completion of the male phase, the spathe dried out and remained attached to the spadix for the next 3-4 weeks before abscission.

\subsection{Floral thermogenesis}

Heat production varied among inflorescences but the temporal patterns were similar (Fig. 4). Temperature recordings inside the floral chamber were slightly higher than ambient temperature during the 4-d monitoring period; the mean difference ranged from 0.77 to $1.22{ }^{\circ} \mathrm{C}$ (S.D. $\left.=0.41-0.78\right)$. We recorded recurrent periods of steady increase in heat production in morning hours and around noon (Fig. 4). The initial peaks of thermogenesis coincided with the female phase (stage II), and the last period of temperature rise coincided with the male phase (stage III). During the peak periods of heat production, temperature inside the floral chamber reached from 1.8 to $4.3^{\circ} \mathrm{C}$ above ambient temperature (Fig. 4).

\subsection{Reproductive phenology}

The population pattern of inflorescence development, anthesis, and fruit dispersal showed well defined peaks (Fig. 5). Production of 
inflorescences and flowering concentrated during the wet season, while seed dispersal occurred during the dry season but showed a peak at the onset of the rainy season. We observed occasional overlap between inflorescences in anthesis in the same individual. The complete reproductive cycle from development to seed dispersal of an inflorescence spanned for nearly 36 weeks ( $\sim 9$ months).

\subsection{Fruit and seed production}

All non-manipulated inflorescences exposed to natural pollination conditions produced fruits and we did not observe abortion of complete inflorescences. In average, an inflorescence of $M$. lentii developed 486.5 ( \pm 99.1 S.D.) fertile flowers, from which $61.4 \%$ $( \pm 16.7$ S.D., range $=21-83 \%)$ turned into fruit under natural pollination. A high percentage (88\%) of those fruits contained one apparently viable seed, and less commonly two (11.5\%) or three seeds $(0.5 \%)$. Six out of the 11 bagged inflorescences developed from one up to 80 fruits, representing an average fruit set of $10 \%$ (range $=1-20 \%$ ). Seeds formed by spontaneous self-pollination were similar in appearance to those sired under natural pollination.

\section{Discussion}

This study is the second documenting Monstera pollination and the first documenting the pollination ecology of Cychrocephalus corvinus; a species from the Mystropini tribe also known as "sap beetles" which have been documented to be mainly palm pollinators (Kirejtshuk and Couturier, 2010).

\subsection{Flowering cycle, spathe behavior, and heat production}

Our results confirm the occurrence of protogyny in Monstera (Chouteau et al., 2007; 2009); a common floral trait among aroids (Mayo et al., 1997). In general, dichogamy is a reproductive mechanism to prevent self-pollination while protogyny particularly encourages cross-pollination (Webb and Lloyd, 1986). The joint period of stigma receptivity and pollen presentation (5 d) in $M$. lentii was similar to reports from the congeneric M. adansonii, $M$. deliciosa (Chouteau et al., 2009) and M. obliqua (Chouteau et al., 2007). Among bisexual aroids Monstera seems to have a short (specialized?) anthesis when compared to 6-14 d in Spathiphyllum (Hentrich et al., 2010; Montalvo and Ackerman, 1986) or up-to a few weeks in some Anthurium species (Croat, 1980; Franz, 2007; Hentrich et al., 2010).

The spathe movement in M. lentii was coordinated with the floral anthesis events. The slow unfurling during the early flowering cycle allowed the formation of the floral chamber, which coincided with the stage of female receptivity; while full opening of the spathe occurred in the male phase. The formation of a floral chamber was not previously reported for the genus (Grayum, 1990; Madison, 1977), but later noticed in M. obliqua (Chouteau et al., 2007), M. adansonii, and M. deliciosa (Chouteau et al., 2009). Earlier, the spathe of Monstera was described as broadly expanded or "boat shape" at maturity and colored. In dried herbarium specimens the floral chamber is not obvious, while in the forest understory it is likely to be ignored because of its green color (Fig. 2B). Only when it is fully expanded and shows the inner white color (Fig. 2C) the spathe becomes noticeable in the forest but, at that time, it advertises the end of the floral cycle.

Thermogenesis in M. lentii showed a cyclic pattern. During the anthesis period, a steady increase in temperature inside the floral chamber occurred during each morning and was highest around noon, coinciding with an increase in ambient temperature. A similar pattern was described in $M$. adansonii and M. deliciosa (Chouteau et al., 2007, 2009). Since the temperature values of the latter species were recorded from the spadix (vs. floral chamber in our study) the absolute differences in heat production are not readily comparable.

Peaks of heat production in $M$. lentii were similar in magnitude during both female and male phase, and there was not an evident higher peak associated to pollen release as found in other Monstera species (Chouteau et al., 2007, 2009). Variation in heat production among inflorescences in $M$. lentii might be related to size differences as suggested by Chouteau et al. (2009). Thermogenesis is frequently related to the emission of volatiles to attract pollinators (Endress, 1994) thus, the pattern of longer heat production in $M$. lentii might function to increase the time of insect attraction during the female phase. Alternatively, prolonged thermogenesis during the residence of the beetles in the floral chamber may represent an energy reward that would keep the insects more active (Seymour et al., 2003), thus increasing the chances that pollen carried by the insects to be deposited on the stigmas. Heat production and the apparent stronger emission of volatiles during male anthesis do not have a single explanation. Temperature may facilitate pollen release from the anthers (Chouteau et al., 2009) or increase body temperature of nitidulid beetles before flying away (Seymour et al., 2003). In addition, stronger volatile scents may function to repel insects and encourage them to visit inflorescences in female phase (Terry et al., 2007), but testing this hypothesis requires quantitative measurement of floral scent chemistry.

\subsection{Insect visitors and pollination}

In our study, nitidulid beetles (Cychrocephalus corvinus) were the most frequent and abundant insects inside inflorescences of $M$. lentii. The beetles' behavior of arriving at the inflorescence during the female phase, being active and moving around on the spadix and departing after the male phase with pollen on their bodies makes them a suitable pollinator. The beetles' small (ca. $5 \mathrm{~mm}$ ) and flattened body allow the insects to enter the floral chamber which they use as a shelter and a place for aggregation and mating. Pollen as food reward for the adult beetles could not be ascertained; however, the mandibles of these beetles rather suggest a predatory habit. We could not investigate the use of $M$. lentii inflorescences as brood site for beetles' larvae. This is an uncommon and rarely collected nitidulid species in Costa Rica, little or almost nothing is known about its natural history (A. Cline, pers. com.).

Nitidulid beetles have been reported as floral visitors and/or pollinators of several aroids, mainly in tropical Asia and Africa (reviewed in Gibernau 2003). In the neotropics, nitidulid beetles have been found in inflorescences of some monoecious aroids mainly pollinated by scarab beetles (García-Robledo et al., 2004; Valerio, 1984); however, they have not been considered as pollinators. Thus far, the work of Chouteau et al. (2007) is the only previous report of nitidulids (Colopterus amputatus) in Monstera. We additionally recovered $C$. corvinus from the floral chambers of $M$. adansonii and $M$. oreophila at the study site. The pollination system of Monstera that emerges from the available data quite differs from other bisexual groups which lack a floral chamber and heat production, such as Anthurium (Franz, 2007; Hentrich et al., 2010; Valerio-Gutiérrez and Villalobos-Solano, 1980) and Spathiphyllum (Hentrich et al., 2010; Williams and Dressler, 1976). However, it rather resembles the pollination mechanism of the monoecious and neotropical Philodendron which is pollinated by scarab beetles instead of nitidulids (Gibernau and Barabé, 2000, 2002; Gibernau et al., 1999; Maia et al., 2010). Interestingly, the pollination system of Monstera seems analogous to that present among several neotropical palms which involves the formation of a floral chamber, heat production and pollination by nitidulid beetles that breed in the inflorescences (Henderson, 1986; Silberbauer-Gottsberger, 1990). Moreover, C. corvinus belongs to the Mystropini tribe (sap 
beetles, Nitidulidae) which have been documented to be mainly palm pollinators (Kirejtshuk and Couturier, 2010).

This study also represents the first report of drosophilid flies associated to inflorescences of Monstera species. In the studied $M$. lentii, the flies entered the floral chamber during the female phase and departed in male phase, which suggests a potential role as pollinators. The relationship between anthophilous flies of the family Drosophilidae with Araceae has been previously observed in several genera; especially in Southeast Asia and Tropical America (see Gibernau 2003; Tsacas and Chassagnard 1992). Drosophilid flies utilize the inflorescences of some aroids as oviposition sites (Valerio 1984; Tsacas and Chassagnard 1992; Vilela 2001); a behavior we could not observe in $M$. lentii.

Stingless bees were the only additional insect group visiting the inflorescences of $M$. lentii but they arrived to collect pollen when the spathe was fully open during male anthesis. Thus, they would be more appropriately regarded as pollen robbers, not pollinators as previously suggested (Madison 1977; Ramírez and Gómez, 1978).

\subsection{Phenology and reproductive success}

Madison (1977) affirmed that the reproductive phenology behavior of Monstera does not seem to show a pronounced seasonality. However, we found that flowering and seed dispersal peaks of $M$. lentii concentrated during the rainy season. Data on flowering phenology of neotropical aroids is meager but reports from Costa Rican populations also show an association with the wettest period, such as in Xanthosoma wendlandii (Valerio 1988), Dieffenbachia oerstedii (Valerio 1983), and D. longispatha (Young, 1986). Both the flowering and seed dispersal peak in $M$. lentii occurred during the time of highest moisture availability. Moisture is an abiotic factor required for the development of reproductive structures and enhances seed germination and early establishment (Rathcke and Lacey, 1985). Whether reproduction of $M$. lentii is also associated to the phenology of the beetle pollinator is unknown. However, a detailed analysis of the phenological behavior of the study species is beyond the scope of this study.

Inflorescences in $M$. lentii produced a relatively high mean fruit set $(61.4 \%)$ under natural pollination conditions, which contrasts with reports from M. obliqua (Chouteau et al., 2007), in which most naturally-pollinated inflorescences $(71 \%)$ aborted. The reasons of this difference in fruit set are not clear, but are possibly related to pollinator density, availability of mates, and resource limitation. In M. lentii, protogyny may be acting as a barrier to selfpollination. Nonetheless, incomplete dichogamy and spontaneous selfing seems plausible in some inflorescences as indicated by the results of the pollinator-exclusion experiment. Although we carried out periodic inspections of the bags to avoid the unwanted entry of insects, additional studies are needed to confirm the occurrence of self pollination in Monstera. Geitonogamous pollination in M. lentii is likely infrequent because of the low anthesis overlap among inflorescences in the same individual. Together, these results suggest a mainly out-crossing mating system in M. lentii.

In summary, the floral morphology, thermogenesis, and anthesis behavior of $M$. lentii conforms to the pollination syndrome of cantharophily (Faegri and van der Pijl 1979; Proctor et al., 1996), which was confirmed by the presence and behavior of the nitidulid beetle Cychrocephalus corvinus (Nitidulidae). However, since drosophilid flies may also be important pollinators, $M$. lentii is likely to exhibit a mixed-pollination system. Further investigations may evaluate the relative efficiency of both pollinator types by performing exclusion experiments and analyses of pollen loads from insects arriving to inflorescences in female phase. In any cases, the reproductive success of M. lentii seems highly dependent on its pollinators. Further studies may also inquire in the natural history of the nitidulid beetles and drosophilid flies to fully understand the nature of this mutualism.

\section{Acknowledgements}

Roberto Cordero (Universidad Nacional de Costa Rica) and Paul Hanson (Universidad de Costa Rica) commented an early manuscript. Carlos Vilela (Universidade de São Paulo, Brazil, drosophilid flies), Paul Hanson (Universidad de Costa Rica, bees), and Andrew Cline (California Department of Food \& Agriculture, USA, nitidulid beetles) identified the insects. The National Meteorological Institute (IMN) kindly provided the weather data. Marc Gibernau provided valuable comments. To the staff of Campo Nacional Escuela Iztarú (Guías y Scouts de Costa Rica) for logistic support. Christian Trejos and Erika Rodriguez provided invaluable assistance in the field. This work was supported by the Vicerrectoría de Investigación from the Universidad de Costa Rica (project 111-B2-041).

\section{References}

Bolaños, R., Watson, V., 1993. Mapa ecológico de Costa Rica, según el sistema de clasificación de Zonas de Vida del mundo de L. R. Holdridge. 1:200 000. Centro Científico Tropical, San José, Costa Rica.

Bown, D., 2000. Aroids: Plants of the Arum Family. Oregon, Timber Press.

Boyce, P., Croat, T., 2016. The Überlist of Araceae, Totals for Published and Estimated Number of Species in Aroid Genera [WWW Document] (last Updat. March 2016) http.//www.aroid.org/genera/160330uberlist.pdf.

Bröderbauer, D., Diaz, A., Weber, A., 2012. Reconstructing the origin and elaboration of insect-trapping inflorescences in the Araceae. Am. J. Bot. 99, 1666-1679, http://dx.doi.org/10.3732/ajb.1200274.

Chartier, M., Gibernau, M., Renner, S.S., 2014. The evolution of pollinator-plant interaction types in the Araceae. Evolution (N. Y.) 68, 1533-1543, http://dx.doi. org/10.1111/evo.12318.

Chouteau, M., McClure, M., Gibernau, M., 2007. Pollination ecology of Monstera obliqua (Araceae) in French Guiana. J. Trop. Ecol. 23, 607-610.

Chouteau, M., Barabé, D., Gibernau, M., 2009. Flowering and thermogenetic cycles in two species of Monstera (Araceae). Bull. Soc. Hist. Nat. Toulouse 145, 1-17.

Croat, T.B., 1980. Flowering behavior of the neotropical genus Anthurium (Araceae) Am. J. Bot. 67, 888-904.

Cusimano, N., Bogner, J., Mayo, S.J., Boyce, P.C., Wong, S.Y., Hesse, M., Hetterscheid, W.L.A., Keating, R.C., French, J.C., 2011. Relationships within the Araceae: comparison of morphological patterns with molecular phylogenies. Am. J. Bot. 98, 654-668, http://dx.doi.org/10.3732/ajb.1000158.

Dafni, A., 1984. Mimicry and deception in pollination. Annu. Rev. Ecol. Syst. 15, 259-278.

Endress, P., 1994. Diversity and Evolutionary Biology of Tropical Flowers. University Press, Cambridge, UK.

Etl, F., Franschitz, A., Aguiar, A.J.C., Schönenberger, J., Dötterl, S., 2017. Perfume-collecting male oil bees? Evidences of a novel pollination system involving Anthurium acutifolium (Araceae) and Paratetrapedia chocoensis (Apidae, Tapinotaspidini). Flora, http://dx.doi.org/10.1016/j.flora.2017.02.020.

Faegri, K., van der Pijl, L., 1979. The Principles of Pollination Ecology. Pergamon Press, Oxford.

Franz, N.M., 2007. Pollination of Anthurium (Araceae) by derelomine flower weevils (Coleoptera: Curculionidae). Rev. Biol. Trop. 55, 269-277.

García-Robledo, C., Kattan, G., Murcia, C., Quintero-Marn, P., 2004. Beetle pollination and fruit predation of Xanthosoma daguense (Araceae) in an Andean cloud forest in Colombia. J. Trop. Ecol. 20, 459-469.

Gibernau, M., Barabé, D., 2000. Thermogenesis in three Philodendron species (Araceae) of French Guiana. Can. J. Bot. 689, 685-689, http://dx.doi.org/10. 1139/cjb-78-5-685.

Gibernau, M., Barabé, D., 2002. Pollination ecology of Philodendron squamiferum (Araceae). Can. J. Bot. 80, 316-320, http://dx.doi.org/10.1139/b02-006.

Gibernau, M., Barabé, D., Cerdan, P., Dejean, A., 1999. Beetle pollination of Philodendron solimoesense (Araceae) in French Guiana. Int. J. Plant Sci. 160, 1135-1143.

Gibernau, M., Chartier, M., Barabé, D., 2010. Recent advances towards an evolutionary comprehension of Araceae pollination. In: Seberg, Petersen, Barfod, Davis (Eds.), Diversity, Phylogeny, and Evolution in the Monocotyledons. Aarhus University Press, Denmark, pp. 101-114.

Gibernau, M., 2003. Pollinators and visitors of aroid inflorescences. Aroideana 26 66-83.

Gibernau, M., 2011. Pollinators and visitors of aroid inflorescences: an addendum. Aroideana 34, 70-83.

Gibernau, M., 2016. Pollinators and visitors of aroid inflorescences III pollinators and visitors of aroid inflorescences III - phylogenetic \& chemical insights. Aroideana 39, 4-22

Gottsberger, G., Amaral, A., 1984. Pollination strategies in brazilian Philodendron species. Ber. Deutsch. Bot. Ges. Bd. 97, 391-410. 
Gottsberger, G., Silberbauer-Gottsberger, I., Dötterl, S., 2013. Pollination and floral scent differentiation in species of the Philodendron bipinnatifidum complex (Araceae). Plant Syst. Evol. 299, 793-809, http://dx.doi.org/10.1007/s00606013-0763-4.

Grayum, M.H., 1990. Evolution and phylogeny of the Araceae. Ann. Missouri Bot. Gard. 77, 628-697.

Grayum, M.H., 2003. Araceae. Manual de Plantas de Costa Rica: Volumen II, Gimnospermas y Monocotiledóneas (Agavaceae-Musaceae). Monogr. Syst. Bot. from Missouri Bot. Gard. 92, 59-200, http://dx.doi.org/10.1007/BF02181026.

Henderson, A., 1986. A review of pollination studies in the Palmae. Bot. Rev. 52, 221-259, http://dx.doi.org/10.1007/BF02860996.

Hentrich, H., Kaiser, R., Gottsberger, G., 2010. Floral biology and reproductive isolation by floral scent in three sympatric aroid species in French Guiana. Plant Biol. 12, 587-596, http://dx.doi.org/10.1111/j.1438-8677.2009.00256.x.

Kirejtshuk, A.G., Couturier, G., 2010. Sap beetles of the tribe Mystropini (Coleoptera: Nitidulidae) associated with South American palm inflorescences. Ann. Soc. Entomol. Fr. 46, 367-421

Madison, M., 1977. A revision of Monstera (Araceae). Contrib. Gray Herb. 207, $1-101$.

Maia, A.C.D., Schlindwein, C., Navarro, D.M.A.F., Gibernau, M., 2010. Pollination of Philodendron acutatum (Araceae) in the Atlantic Forest of Northeastern Brazil: a single scarab beetle species guarantees high fruit set. Int. J. Plant Sci. 171, $740-748$.

Mayo, S.J., Bogner, J., Boyce, P.C., 1997. The Genera of Araceae. The European Union by Continental Printing, Belgium.

Montalvo, A.M., Ackerman, J.D., 1986. Relative pollinator effectiveness and evolution of floral traits in Spathiphyllum friedrichsthalii (Araceae). Am. J. Bot. 73, 1665-1676.

Proctor, M., Yeo, P., Lack, A., 1996. The Natural History of Pollination. Timber Press, Oregon.

Ramírez, W., Gómez, P.L.D., 1978. Production of nectar and gums by flowers of Monstera deliciosa (Araceae) and of some species of Clusia (Guttiferae) collected by new world Trigona bees. Brenesia 14-15, 407-412.

Rathcke, B., Lacey, E.P., 1985. Phenological patterns of terrestrial plants. Ann. Rev. Ecol. Syst. 16, 179-214.
Sánchez, González J., Durán Alvarado, F., Vega Araya, G., 2008. Diversidad de Plantas, Mamíferos y Mariposas en los Cerros de La Carpintera, Costa Rica. Dep. Hist. Nat. Mus. Nac. Costa Rica (98 pp).

Seymour, R.S., White, C.R., Gibernau, M., 2003. Heat reward for insect pollinators. Nature 426, 243-244.

Seymour, R.S., 1999. Pattern of respiration by intact inflorescences of the thermogenic arum lily Philodendron selloum. J. Exp. Bot. 50, 845-852, http://dx. doi.org/10.1093/jxb/50.335.845.

Silberbauer-Gottsberger, I., 1990. Pollination and evolution in palms. Phyton (B. Aires) 30, 213-233.

Terry, I., Walter, G.H., Moore, C., Roemer, R., Hull, C., 2007. Odor-mediated push-pull pollination in cycads. Science 318, 70, http://dx.doi.org/10.1126/ science. 1145147.

Tsacas, L., Chassagnard, M., 1992. Les relations Araceae-Drosophilidae. Drosophila aracea une espèce anthophile associée à l'aracée Xanthosoma robustum au Mexique (Diptera:Drosophilidae). Ann. la Société Entomol. Fr. 28, 421-439.

Valerio, C.E., 1983. Fenología y eficiencia reproductiva de Dieffenbachia oerstedii Schott (Monocotyledonae: Araceae) en Costa Rica. Rev. Biol. Trop. 31, 263-267.

Valerio, C.E., 1984. Insect visitors to the inflorescence of the aroid Dieffenbachia oerstedii (Araceae) in Costa Rica. Brenesia 22, 139-146.

Valerio, C.E., 1988. Notes on phenology and pollination of Xanthosoma wendlandii (Araceae) in Costa Rica. Rev. Biol. Trop. 36, 55-61.

Valerio-Gutiérrez, C.E., Villalobos-Solano, E.M., 1980. Polinización y eficiencia reproductiva en Anthurium scandens (Araceae). Brenesia 18, 137-146.

Vilela, C.R., 2001. Breeding sites of Neotropical Drosophilidae (Diptera). III. Rooting infructescences of Philodendron bipinnatifidum (Araceae). Rev. Bras. Entomol. $45,339-344$

Webb, C.J., Lloyd, D.G., 1986. The avoidance of interference between the presentation of pollen and stigmas in angiosperms II Herkogamy. New Zealand J. Bot. 24, 163-178.

Williams, N.H., Dressler, R.L., 1976. Euglossine pollination of Spathiphyllum (Araceae). Selbyana 2, 349-356.

Young, J., 1986. Beetle pollination of Dieffenbachia longispatha (Araceae). Am. J. Bot. 73, 931-944. 